\title{
MELT RELATED DEFECTS IN ALLOY 706 AND THEIR EFFECTS ON MECHANICAL PROPERTIES
}

\author{
Samuel V. Thamboo
}

General Electric Company, Schenectady, NY 12345

\begin{abstract}
Alloy 706 as many other superalloys is melted by Vacuum Induction Melting plus Electro-Slag Remelting (ESR) or Vacuum Arc Remelting (VAR) or both. The remelting process (ESR or VAR) can introduce segregation type of defects in the material. These defects could be freckles or white spots. Such defects have been observed in many other superalloys. These defects can have significant effects on the mechanical properties of the alloy under specific conditions. This paper summarizes results of studies made on the effects of such defects on the mechanical properties.

Significant difference has been observed on the effect of solidification versus discrete white spots on the LCF characteristics of the alloy. A short review of the mechanisms of formation of these defects together with controls to minimize them is also presented.
\end{abstract}

Superalloys $718,625,706$ and Various Derivatives Edited by E.A. Loria

The Mincrals, Metals \&\& Matcrials Society, 1994 


\section{Introduction}

Alloy 706 applications for the large land based gas turbines require very large ingot sizes. The diameter of the ingots can be as high as 40 inches and the ship weight can be as high as 30,000 lbs. The manufacturing process for the ingots usually includes vacuum induction melting followed by electroslag re-melting or vacuum arc re-melting or both. The melting and re-melting processes can introduce segregation type of defects that can have a significant effect on the life of the parts made from such ingots. The segregation related defects observed in Alloy 706 ingots include freckles and white spots. Such defects have also been observed in other nickel base alloys such as Alloy 718 , Waspalloy.

Freckles are solute rich areas in an ingot. Flemings and co-workers ${ }^{1-2}$ have shown that they are formed due to flow of solute rich inter-dendritic fluid in the mushy zone. The flow of this solute rich fluid occurs due to density differences within the fluid and also due to electromagnetic forces. Freckles contain a much higher concentration of niobium and also have been observed to contain Laves phase and delta phase in Alloy 718. Freckles cannot be removed by any practical thermomechanical process.

White spots in nickel base superalloys are solute lean regions. On an etched surface they appear lighter than the base material and hence the name white spot. There has been a lot of work done in recent years in the characterization and classification of white spots found in Alloy 718. The white spots may in some cases contain oxides, nitrides and other inclusions. Such white spots are classified as "dirty" white spots. White spots that do not contain such inclusions are classified as "clean" white spots.

Clean white spots can be further classified ${ }^{3}$ as:

1. Discrete white spots

2. Diffuse white spots

3. Solidification white spots

Discrete white spots are characterized by a distinct boundary between the matrix and the white spot. Diffuse white spots are characterized by an indistinct boundary between the matrix and the white spot. The diffuse white spots also are observed to have a dendritic appearance with light and dark areas. Solidification white spots are also characterized by a diffuse or indistinct boundary. They have been often observed to have a linear, hooked or ring shape. The solidification white spots are typically found from mid-radius to surface of the ingots while discrete white spots and diffuse white spots are found usually from mid-radius to center.

This paper summarizes the characteristics and the effect on mechanical properties of these defects in Alloy 706.

\section{Material}

Alloy 706 used for land based large gas turbine applications typically has the following composition.

$\begin{array}{ccccccccc}\mathbf{C} & \mathbf{M n} & \mathbf{S i} & \mathbf{C r} & \mathbf{N i} & \mathbf{F e} & \mathbf{T i} & \mathbf{A l} & \mathbf{N b}+\mathbf{T a} \\ 0.02 & 0.20 & 0.06 & 16.0 & 41.5 & 40.0 & 1.7 & 0.2 & 3.0\end{array}$


The melting processes used for the materials in this study include vacuum induction melting followed by electroslag remelting or vacuum arc remelting or both. The ingots were converted to billet by an upset and draw technique. Finish forging was done on hydraulic press through a number of steps. Heat treatment included a solution treatment and quench step followed by a double age.

It was difficult to get specimens with solidification white spots from forgings. Therefore small heats (approximately 50 pounds each) were prepared with compositions to match the composition of solidification white spots observed in large ingots. The trial heats were vacuum induction melted. These ingots were rolled into bars and then heat treated in exactly the same way as the larger forgings.

Mechanical testing of specimens were made as per ASTM standards. Standard metallographic techniques were used to observe and analyze the samples.

\section{$\underline{\text { Results }}$}

\section{Freckles}

Figure 1 is a photograph of a large diameter VIM+ESR billet with several freckles. It can be seen that the freckles do not favor any specific radial location of the ingot. Some of these freckles are associated with cracks. Figure 2 is micrograph of a specimen with a freckle after finish forging and heat treatment. The freckle is in the fine grained region. The presence of numerous particles in the freckle region pin the grain boundaries to a very fine grain size. Figure 3 is a micrograph of a freckle at a higher magnification. The large particles were typically nitrides and carbonitrides of niobium and titanium. The smaller and rounder particles were typically Laves phase (hexagonal $\left.(\mathrm{Fe}, \mathrm{Ni}, \mathrm{Cr})_{2}(\mathrm{Nb}, \mathrm{Ti})\right)$.

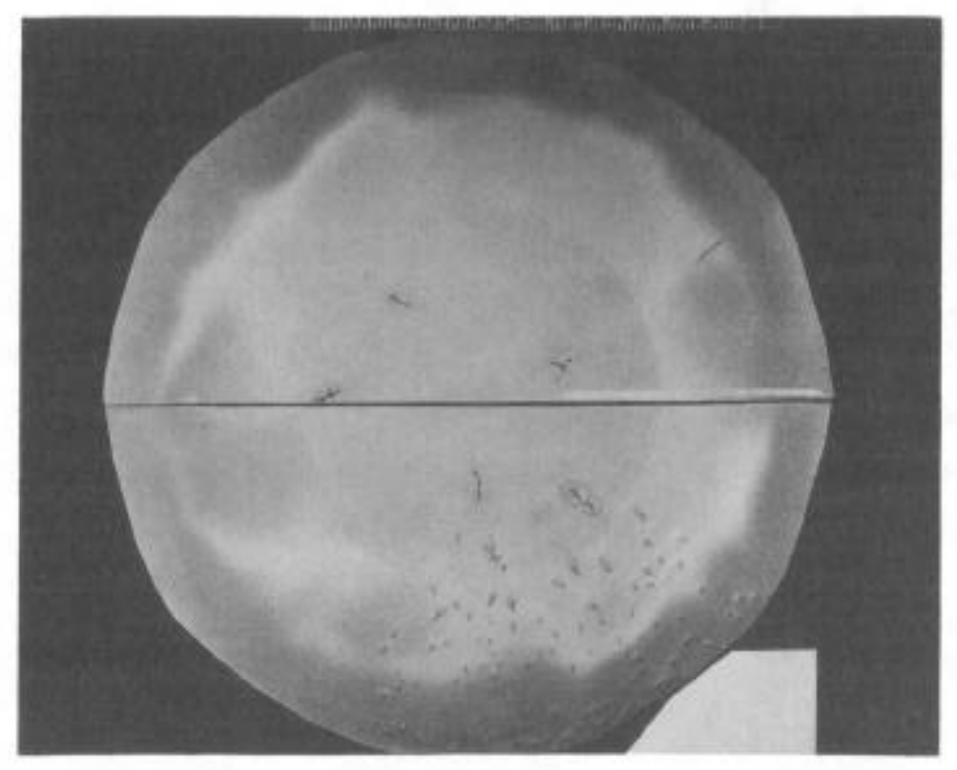

Figure 1 - Transverse macro-etched section from a billet processed by VIM+ESR. The dark etching spots are freckles. 


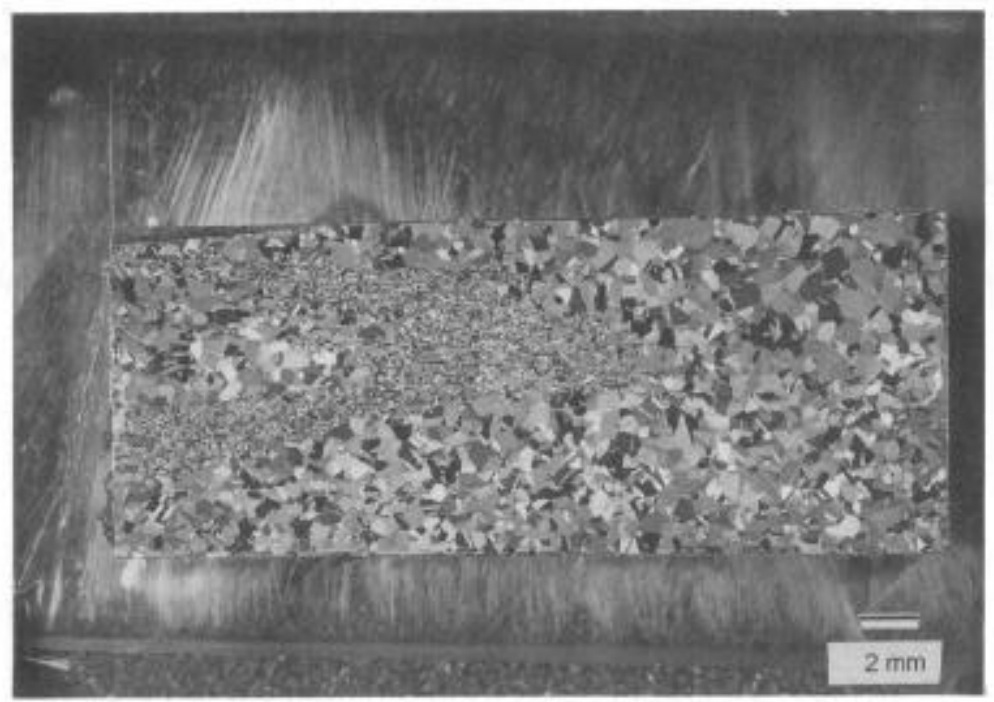

Figure 2 - Sectioned from a finish forged and heat treated material with a freckle. The numerous particles in the freckle pin the grain boundaries to a very fine grain size.

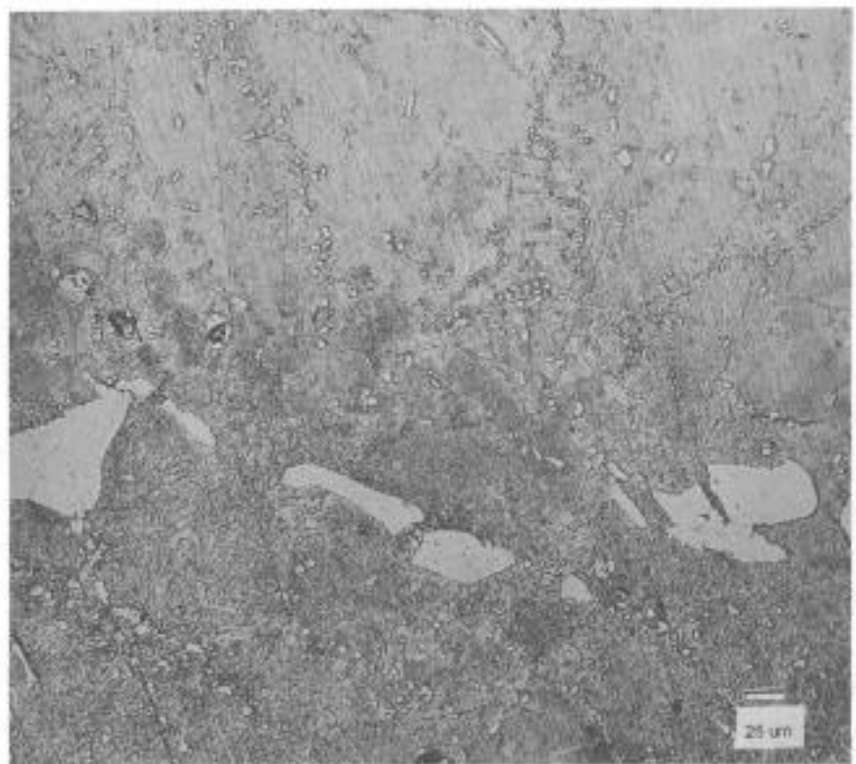

Figure 3 - Higher magnification of the freckle from a finish forged and heat treated material. The large particles are carbides or carbo-nitrides, the smaller rounder particles are Laves phase and the plate like precipitates are eta phase. Etchant - Kallings 
The particles in the form of plates were the eta phase $(\mathrm{Fe}, \mathrm{Ni}, \mathrm{Cr})_{3}(\mathrm{Ti}, \mathrm{Nb})$. Figure 4 shows SEM photos of the extracted particles from the freckles.

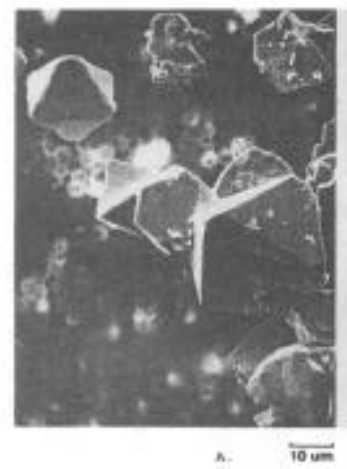

A. carbo-nitrides of niobium and titanium

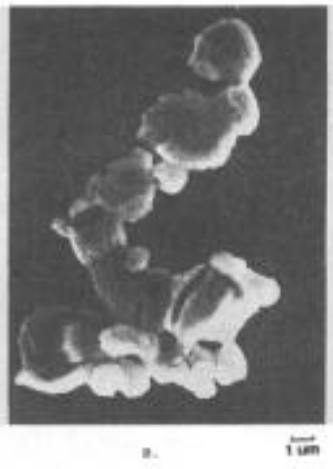

B. Laves phase.

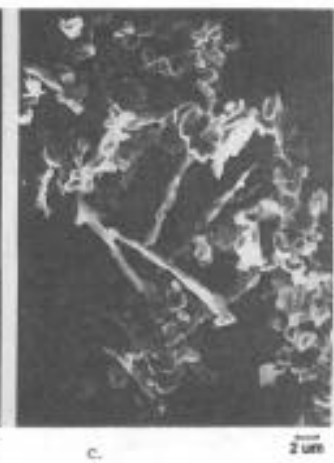

C) Eta phase.

Figure 4-SEM images of extracted particles from a freckle

In a finish forged and heat treated forging freckles usually lie along the an axis perpendicular the forging axis. In some case cracks were also observed at some freckles. The orientation of the freckles has a significant effect on the properties. Room temperature and $750 \mathrm{~F}$ tensile tests conducted in the longitudinal (L-R) orientation (freckles perpendicular to the loading axis) showed a dramatic drop in ductility (Table I). The reduction-in-area dropped as low as 2.4 percent for both room temperature and $750^{\circ} \mathrm{F}$ tests. A drop in ultimate tensile strength of approximately $10-15$ percent was also observed but the yield strength was practically unaffected. There was no significant effect in tensile properties for tests in the tangential (C-R) orientation (freckles parallel to the loading axis).

\section{TABLE I - Comparison of Longitudinal Tensile Properties} for Material With Freckle and No Freckles.

\begin{tabular}{|lllrrr|}
\hline Specimen ID & Temp. & Vield & U.T.S. & \%Elongation & \%RA \\
\hline No Freckle 1 & 75 F & 146.3 & 172.1 & $7.0^{*}$ & 4.7 \\
\hline No Freckle 2 & " & 146.8 & 175.9 & 11.0 & 15.2 \\
\hline Freckle 1 & " & 146.5 & 149.8 & 1.0 & 6.2 \\
\hline Freckle 2 & " & 145.7 & 155.9 & 2.0 & 2.4 \\
\hline No Freckle 3 & $750 \mathrm{~F}$ & 131.4 & 159.1 & 18.0 & 30.4 \\
\hline No Freckle 4 & " & 130.1 & 158.6 & 18.0 & 31.8 \\
\hline Freckle 3 & " & 129.8 & 137.4 & 2.0 & 2.4 \\
\hline Freckle 4 & " & 127.3 & 138.6 & 3.0 & 5.5 \\
\hline
\end{tabular}

- Specimen broke outside gage length and had cracks away from the fracture surface

The fracture toughness (L-R orientation) of material with freckles exhibited approximately $50 \%$ drop in $\mathrm{K}_{\mathrm{IC}}$ for tests when the crack was able to follow the plane of the crack. However when the cracks were not along the freckle there was no significant difference compared to good material. Specimens tested along the C-R direction did not show any drop in fracture toughness. 
The results of fatigue crack growth rate tests show that the crack growth rate increased when the crack grew along the freckle. This is demonstrated in Tigure 5. No effect on the growth rate was observed for the $\mathrm{C}-\mathrm{R}$ orientation. In the L-R orientation the crack growth rate showed an increase when the crack grew along the freckle. One L-R specimen shows the effect on crack growth rate when the crack encounters a freckle. Examination of the fracture surface confirmed that the jump in crack grow th rate occurred when the crack reached the freckle and further grow th continued along the freckle. Both L-R specimens failed at a Kq of $42 \mathrm{ksi} \sqrt{\mathrm{in}}$.

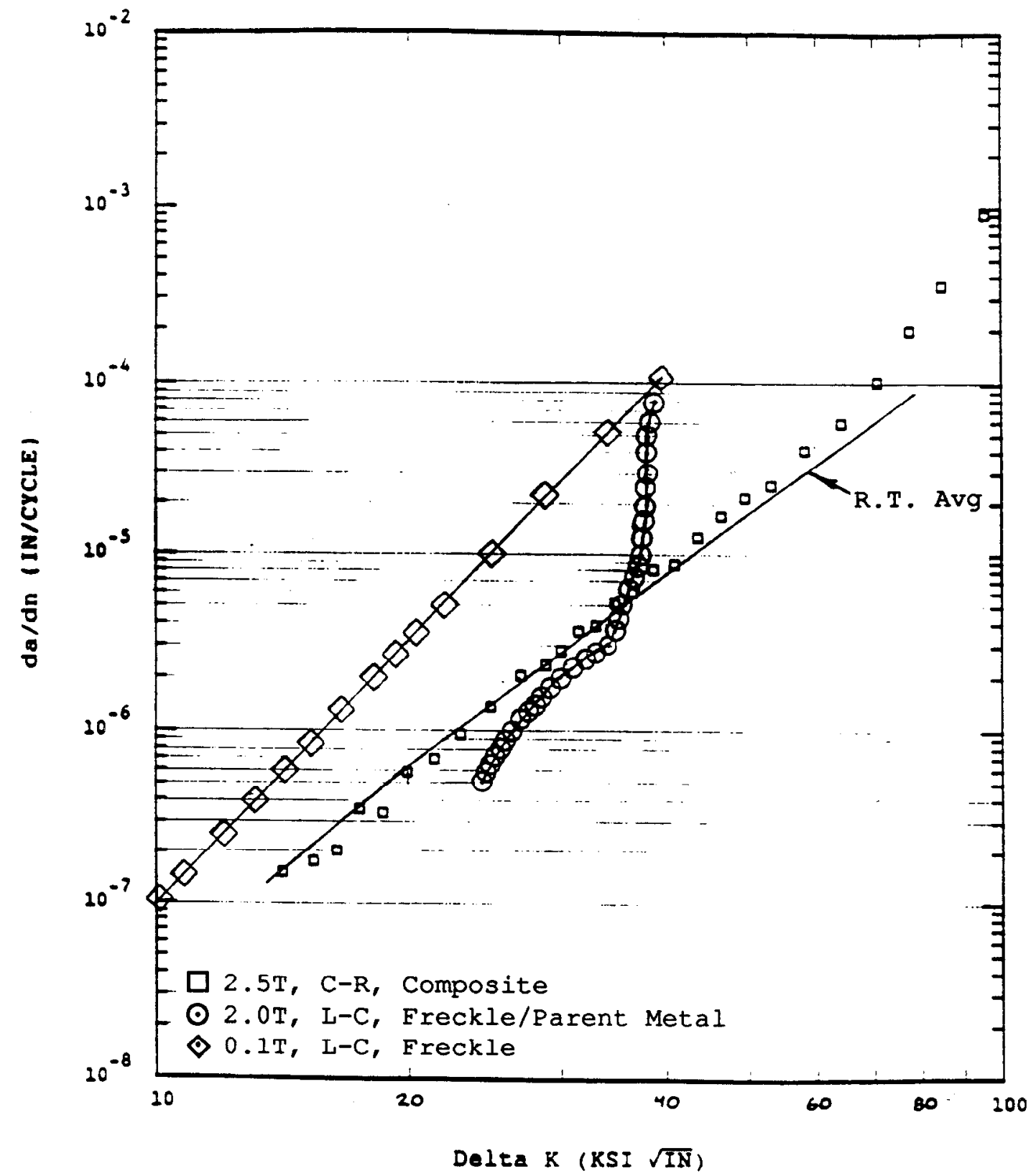

Figure 5-Crack growth rate curves at room temperature for material with freckles in the $L-C$ and $C-R$ orientations. The average line represents the typical curve for material without any freckles. Both L-C specimens fractured at a $\mathrm{Kq}$ of $42 \mathrm{ksi} \sqrt{\mathrm{in}}$. 


\section{Discrete White Spots}

Figure 6 shows a dirty discrete white spot after finish forging and heat treatment. The location of this dirty white spot was near the center of the ingot. Numerous oxide nitride stingers were observed in this white spot. Because of the excessive etching and the higher magnification the boundary between the matrix and the white spot does not appear distinct. At lower magnifications and on a macro-etched surface this white spot had a clear and distinct boundary with the matrix. The grain size within the white spot region and the matrix are about the same. This is different from Alloy 718 where white spots have a coarser grain than the matrix size.

A clean discrete white spot is shown in Figure 7. The grain size again does not show any difference between white spot and matrix material. The location of this white spot was also near the center of the forging.

Fatigue crack growth rate testing was done on compact tension type of specimens. The tests were done at room temperature at $10 \mathrm{~Hz}$ with $\mathrm{R}=0.1$. The specimen with the dirty white spot was tested with constant $\mathrm{K}$ while the specimen with the clean white spot was tested with increasing $\mathrm{K}$. After testing the broken specimens were etched to confirm the location of the white spots. In both cases the crack propagated through the white spots. Companion specimens through parent material were machined and tested from the same forging for comparison. The fatigue crack growth rate through the white spot remained the same as the parent material. No change in crack growth rate was observed even when the crack was propagating through the area of high inclusions in the specimen with dirty white spot.

LCF Tests were done at $650^{\circ} \mathrm{F}$ under strain control with A-ratio $=1$ and $20 \mathrm{cpm}$ triangular wave form. Tests were done at two strain ranges $0.5 \%$ and $0.7 \%$. LCF testing was done only on specimens with clean white spots. The results of the LCF tests are given in Table II. The specimens with the white spots show a decrease in life at the $0.7 \%$ strain range. At $0.5 \%$ strain range there appears to be no significant difference in life between the specimens with the white spots and the parent material.

\section{TABLE II - 650 FLCF Results of Material With and Without Discrete White Spots}

$A=1 ; 20 \mathrm{cpm}$

\begin{tabular}{|c|c|c|c|c|}
\hline I.D. & Location & Strain Range & $\mathrm{Ni}^{*}$ & Ni Avg. \\
\hline $1 \mathrm{~W}$ & White Spot & 0.7 & 2757 & 2278 \\
\hline $2 W$ & $"$ & $"$ & 2530 & \\
\hline $6 \mathrm{~W}$ & " & "I & 1940 & \\
\hline $7 \mathrm{WW}$ & “ & $"$ & 2039 & \\
\hline $8 W$ & “ & $"$ & 2127 & \\
\hline $1 \mathrm{P}$ & Parent Material & “ & 4212 & 4054 \\
\hline $2 \mathrm{P}$ & " & $"$ & 3810 & \\
\hline $5 P$ & $"$ & $"$ & 4142 & \\
\hline $3 W$ & White Spot & 0.5 & 14257 & 15124 \\
\hline $4 W$ & 4 & $"$ & 15992 & \\
\hline $3 P$ & Parent Material & $" 1$ & 14018 & 14969 \\
\hline $4 \mathrm{P}$ & 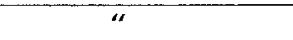 & “ & 15920 & \\
\hline
\end{tabular}

${ }^{*} \mathrm{Ni}=$ Number of cycles to initiation 


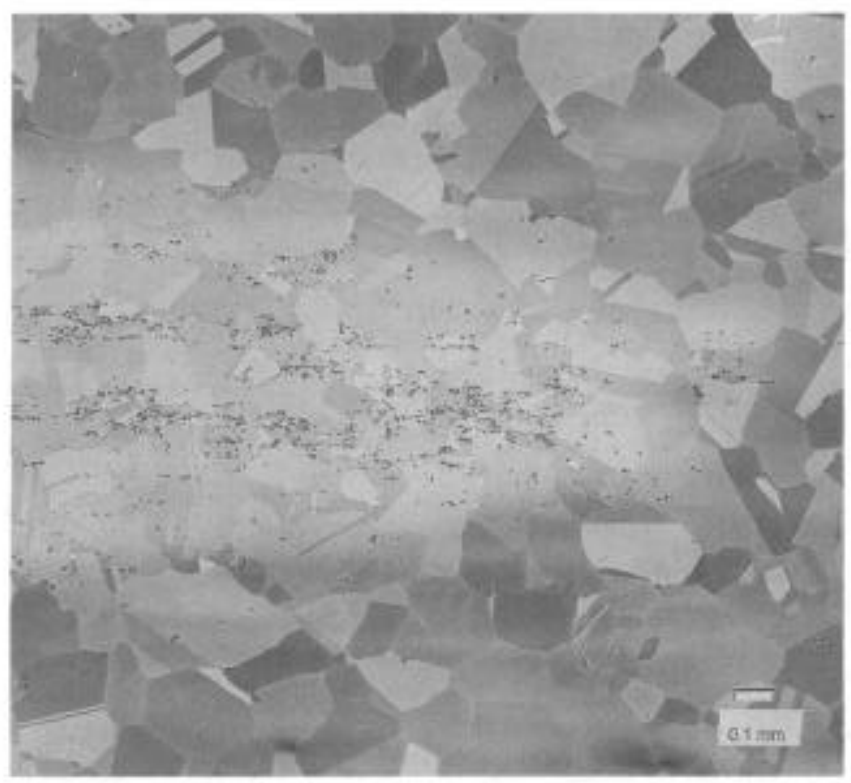

Figure 6-Dirty white spot after finish forging and heat treatment. The inc/usions were typically oxides and nitrides.

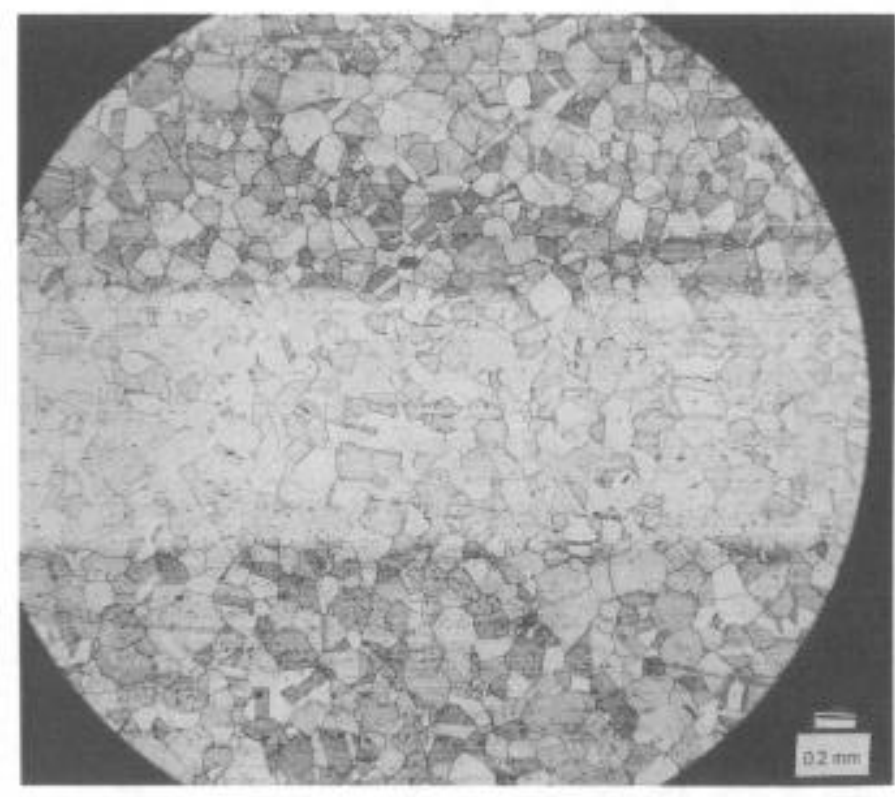

Figure 7 - Clean discrete white spot after finish forging and heat treatment. The grain size within the white spot is the same as the matrix. 
A few specimens were tested with two extensometers at the higher strain range. This was done to detect if there was any partitioning of strain leading to higher strains across the white spots. The second extensometer was located just across the white spot. No significant difference could be detected between the two extensometers.

All the specimens with the white spots fractured at the white spot. This was verified by macroetching one half of each specimen. Initiation occuered within the white spot and did not occur at the white spot-parent material interface. There was also no significant difference in the fracture characteristics between the white spot and parent material specimen. The fracture surfaces were faceted showing a transgranular crystallographic fracture which is typical for Alloy 706. The initiation sites were at the surface for both cases. The initiation sites were not associated with any defects.

\section{Solidification White Spots}

Solidification white spots have only been observed between mid-radius and surface of the ingots. They have a linear, hooked or ring appearance. Figure 8 is a photograph of a typical solidification white spot observed in an ingot slice. The spots are relatively small in dimension compared to the discrete white spots. It was therefore impossible to make test specimens because of the small size of the spots. So it was decided to melt small heats and test them instead. Three experimental heats were made. The chemical composition of each heat is given in Table III. One heat represented typical white spot compositions measured in large ingots. The second heat had a composition leaner in hardener elements than the first and it represented a worst case situation for a solidification white spot. The third heat had the chemical composition of typical Alloy 706 ingots. The heats were approximately 50 pounds each and were vacuum induction melted. They were rolled into $5 / 8$ inch diameter bars at $1950^{\circ} \mathrm{F}$. The bars were then given the typical solution heat treatment plus age of a large forgings.

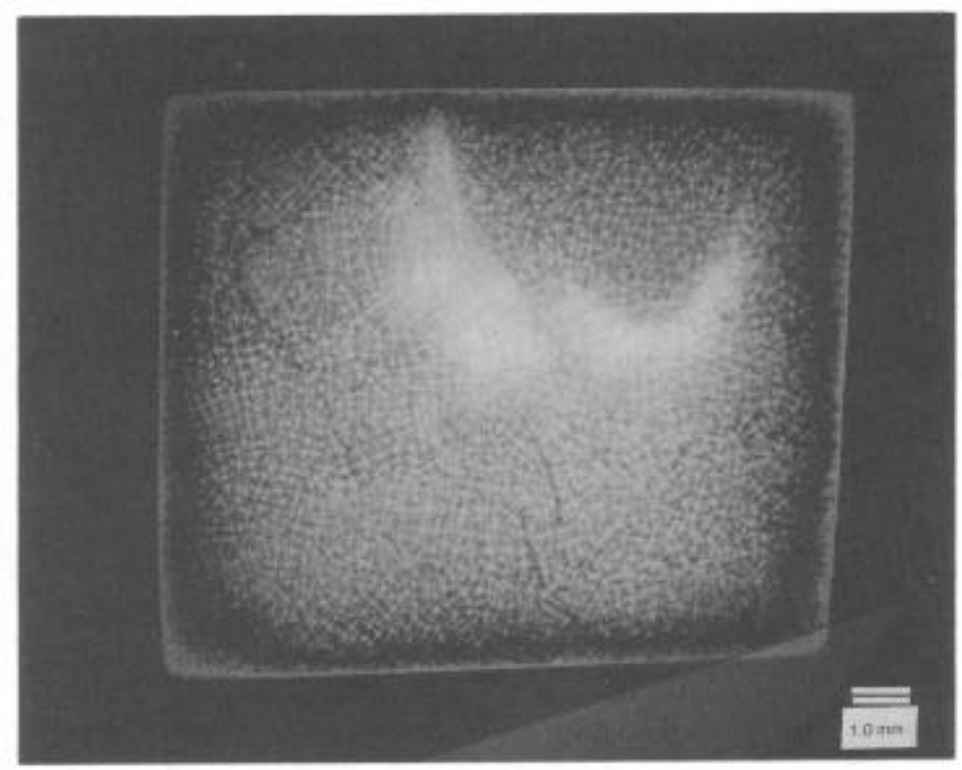

Figure 8- Typical solidification white spot observed in an ingot. Other commonly observed shapes were rings, hooks or lines. 
TABLE III - Chemical Composition of Trial Heats to Simulate White Spot Chemistry

\begin{tabular}{|lccc|}
\hline Element & Base Chemistry* & Sol. White Spot ${ }^{* *}$ & Lean White Spot $^{* * *}$ \\
\hline Titanium & 1.65 & 1.46 & 1.25 \\
\hline Niobium & 3.00 & 2.49 & 2.10 \\
\hline
\end{tabular}

All other elements were kept at the same level and at the nominal composition of Alloy 706. The level of Iron was adjusted to make up differences.

\author{
* Base Chem - Base chemistry of IN706 \\ ** Sol. W.S. - Typical solidification white spot chemistry \\ *** Lean W.S. - Expected lower extreme of solidification white spot
}

The tensile properties of the three heats at three different temperatures are listed in Table IV. A decrease in yield strength and tensile strength is observed with decreased hardener content. This is associated with an increase in percentage elongation and percentage reduction-in-area. This trend is consistent at all three temperatures tested.

TABLEN - Tensile Properties of Trial Heats to Simulate Solidification White Spots

\begin{tabular}{|lccccc|}
\hline Chemistry & Temp $^{\circ} \boldsymbol{F}$ & UTS & 0.2\%YS & $\%$ E & $\%$ RA \\
\hline Base Chem & 72 & 184.5 & 133.0 & 21.6 & 37.4 \\
\hline Sol. W.S. & “ & 176.3 & 126.2 & 23.7 & 41.2 \\
\hline Lean W.S. & " & 168.6 & 117.6 & 26.7 & 50.7 \\
\hline Base Chem & 650 & 166.9 & 118.9 & 19.3 & 47.7 \\
\hline Sol. W.S. & " & 158.1 & 112.6 & 22.0 & 51.0 \\
\hline Lean W.S. & " & 150.4 & 104.2 & 24.5 & 54.1 \\
\hline Base Chem & 900 & 160.7 & 113.4 & 19.6 & 49.8 \\
\hline Sol. W.S. & $"$ & 152.7 & 106.3 & 22.5 & 52.5 \\
\hline Lean W.S. & " & 144.4 & 99.7 & 24.9 & 54.1 \\
\hline
\end{tabular}

$\mathrm{LCF}$ testing was done at $650^{\circ} \mathrm{F}$ and $900^{\circ} \mathrm{F}$. The results are given in Table $\mathrm{V}$ and Table VI. At the $0.7 \%$ strain range at $650^{\circ} \mathrm{F}$ the LCF life indicates an increase in life with decreasing strength. However at $0.5 \%$ strain the trend is not consistent with strength. Similarly at $900^{\circ} \mathrm{F}$ the $0.7 \%$ strain tests show correlation with strength while the $0.5 \%$ does not show a consistent correlation. 
TABLE V - $650^{\circ}$ F LCF Test Results of Trial Heats to Simulate Solidification White Spots

$\mathrm{A}=1 ; 20 \mathrm{cpm}$

\begin{tabular}{|c|c|c|c|}
\hline Strain Range & Chemistry & $\mathrm{Ni}$ & Avg. Ni \\
\hline 0.7 & Base Chemistry & 3112 & 3604 \\
\hline$"$ & $"$ & 3682 & \\
\hline$"$ & $"$ & 4019 & \\
\hline$“$ & Sol. White Spot & 4138 & 3976 \\
\hline$"$ & " & 4231 & \\
\hline$"$ & $"$ & 3561 & \\
\hline$"$ & Lean White Spot & 6548 & 5761 \\
\hline " & " & 5158 & \\
\hline$"$ & " & 5578 & \\
\hline 0.5 & Base Chemistry & 20772 & 18612 \\
\hline$"$ & $"$ & 17888 & \\
\hline “ & “ & 17178 & \\
\hline “ & Sol. White Spot & 14946 & 14055 \\
\hline$"$ & $"$ & 12199 & \\
\hline$"$ & $"$ & 15020 & \\
\hline$"$ & Lean White Spot & 20612 & 18503 \\
\hline$"$ & 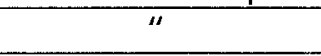 & 17458 & \\
\hline " & $"$ & 17440 & \\
\hline
\end{tabular}

TABLE VI-900 FLCF Test Results of Trial Heats to Simulate Solidification White Spots

\begin{tabular}{|c|c|c|c|}
\hline Strain Range & Chemistry & $\mathrm{Ni}$ & Avg. $\mathrm{Ni}$ \\
\hline 0.7 & Base Chemistry & 4256 & 4551 \\
\hline$"$ & “ & 4679 & \\
\hline$" 1$ & $"$ & 4718 & \\
\hline$" 1$ & Sol. White Spot & 5102 & 5110 \\
\hline$"$ & $"$ & 4743 & \\
\hline$"$ & $"$ & 5485 & \\
\hline$"$ & Lean White Spot & 9274 & 8421 \\
\hline$"$ & “ & 7685 & \\
\hline$" 1$ & $"$ & 8304 & \\
\hline 0.5 & Base Chemistry & 23337 & 22035 \\
\hline$"$ & " & 21646 & \\
\hline$" 4$ & $"$ & 21124 & \\
\hline$"$ & Sol. White Spot & 25897 & 20078 \\
\hline$"$ & 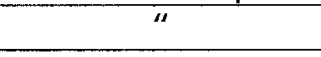 & 17698 & \\
\hline$"$ & $"$ & 16639 & \\
\hline$"$ & Lean White Spot & 31203 & 27611 \\
\hline$"$ & $"$ & 24230 & \\
\hline “ & $"$ & 27400 & \\
\hline
\end{tabular}


$\underline{\text { Discussions }}$

\section{Freckles}

Freckles originate during the re-melting step (ESR or VAR). The freckles contain a high concentration of niobium which precipitates as Laves phase, carbo-nitrides or eta phase. The high stability and the low diffusion rate of niobium makes it virtually impossible to remove freckles by any kind of thermo-mechanical treatment. Therefore it is important to eliminate freckle formation at the remelting step.

$\mathrm{Yu}$ and co-workers ${ }^{5-6}$ have shown that the tendency for freckle formation is higher in ESR than in VAR. This is because of the differences in pool profile between the two melting processes. In general deeper V-shaped pools are observed in ESR while the VAR pool profile is in general shallower and U-shaped. Deeper pools have a prolonged mushy zone and severe temperature gradients which enhance inter-dendritic fluid flow. High power input levels in ESR or VAR make the situation worse because they make the pools deeper. The use of high power inputs (or melt rate) also introduce higher electromagnetic forces which could increase the chances for inter-dendritic fluid flow. The inter-dendritic flow could also be enhanced by localized hot spots due to uneven arcs caused by cracked electrodes. The use of a sound electrode is also therefore very important. The use of triple melting which involves vacuum induction melting followed by electroslag remelting followed by vacuum arc melting has been found to eliminate freckle formation. The use of a low power input in the VAR step helps in eliminating freckles. Hosami et al ${ }^{4}$ have shown that by increasing heat transfer at the ingot crucible interface through higher helium pressure cooling it is possible to make the pool achieve a more shallow profile. As discussed above this would also contribute toward eliminating freckles.

In a finish forged part the freckles usually lie along the forging flow lines. The effect on mechanical properties therefore varies significantly with orientation of testing. Therefore tests have to be done in the correct orientation to determine the effect on properties. Freckles have a very serious impact on the mechanical properties of Alloy 706. The presence of the deleterious phases affects ductility and fracture toughness and crack growth rates dramatically. In addition some freckles can develop cracks during the forge process leading to pre-existing flaws in the part.

\section{Discrete White Spots}

White spots originate in the vacuum arc melting step of the process. Several mechanisms have been proposed for the formation of discrete white $\operatorname{spots}^{5-6}$. They are :

1. Detachment of pieces from the solidifying edge of the ingot pool.

2. Fall-in from the crown of spatter around the electrode top.

3. Fall-in of dendrite arms or broken sections from a cast electrode.

The first two case could create discrete white spots which are dirty because of pickup of material from the crucible wall. In all cases the solid metal which falls into the pool rapidly moves to the center of the ingot because of the shape of the pool and the higher density of the solid metal. Discrete white spots are therefore always observed in the center to mid-radius location of the ingot. The use of a sound remelted electrode ingot (i.e. triple melting) mostly eliminates the third case. It would appear that a higher power input would minimize the discrete white spot problem because the fall-ins would completely melt in the pool. But as mentioned above deeper pools could increase the risk for freckles and therefore increasing melt rate is not a good way of controlling discrete white spots. 
The presence of clean or dirty discrete white spots have not shown any effect on the fatigue crack growth rates. However the presence of inclusions in the dirty white spot can lead to crack initiation and therefore reduced LCF life. In the case of clean white spots, it has been reported that clean white spots reduce LCF life in Alloy 718 even at low $(0.5 \%)$ strain ranges ${ }^{7-8}$. Alloy 706 is depleted in niobium and titanium in a similar way as Alloy 718 . Therefore we might expect the same behavior. However there is an important difference between Alloy 718 and Alloy 706. The Alloy 718 mentioned in these reports were all processed for fine grains (ASTM 8-10). This process involves forging below the delta solvus to dynamically recrystallize the structure and use the delta precipitates to pin the grain boundaries. The depletion of niobium causes a local lowering of the delta solvus in the white spot region. At the forging temperature the white spot could be actually above the delta solvus for the local area. Thus there would be no delta precipitates to pin the grain boundaries within the white spot. The result is that the white spot regions have relatively coarse grains (ASTM 3-5) compared to the rest of the matrix?

This situation does not occur in Alloy 706 because forging is done above the eta solvus where there are no phases to pin the boundaries. Therefore there is no grain size difference between the white spot and the matrix. The grains are uniform ASTM 3-5. It is known that larger grain sizes decrease LCF life across all strain ranges ${ }^{7}$. The decrease observed in LCF life in Alloy 718 due to white spots could therefore be due to grain size difference between white spot and matrix. This grain size difference is not observed in Alloy 706 and therefore no difference is observed at the low strain ranges.

However it is not completely clear what is happening at the high strain range. The interface between the matrix and the white spot did not play a role in reduced LCF life because the fracture always occurred within the white spot. The discrete white spot region is expected to have a significantly lower yield strength and higher ductility because of the low hardener content. Therefore we should actually expect an increase in LCF life as in the case of the homogeneous material with the low hardener content (Table IV). A possible explanation could be that in a specimen with a white spot the strain partitions in such a way that the white spot actually sees a higher strain range than recorded by the extensometer. This could not be confirmed by the double extensometer method. A finite element modeling of an LCF specimen with a white spot was made to determine if there could be significant variations in strain along the gage length..

The model used the tensile properties of the white spot as equal to the lean white spot from Table IV. At maximum displacement $(0.7 \%$ strain) the model shows strain partioning with peak strains at the center of the white spot exceeding $1.1 \%$ (Figure 9 ). This variation also appears across a short distance and it would be very difficult for an extensometer to accurately measure the strain. Actual discrete white spots could be more severely depleted in hardener elements than the lean white spot material used in the model. Therefore the strain partitioning could actually get worse in some cases.

\section{$\underline{\text { Solidification White Spots }}$}

The formation mechanism of solidification white spots is not completely clear. Shved ${ }^{9}$ has recently proposed a mechanism which involves diffusion of atoms across the liquid-solid boundary around splash beads. The splash beads are themselves the same composition as the melt. However when they fall into the melt pool the diffusion of hardener elements into the liquid leads to their depletion around the splash bead. This theory explains the ring shapes commonly found in solidification white spots. The hooked and linear shapes also found in solidification white spots could be sectional views of the same feature. Because of the pool profile the splash beads near the center are more likely to completely melt and dissolve in the pool. Therefore the solidification white spots are typically found from mid-radius to surface of the ingot and not near the center. 
A solidification white spot is less depleted in hardener elements than a discrete white $\operatorname{spot}^{10}$. Actual chemistry analysis of solidification white spots showed the results were fairly consistent and very close to the composition of the simulated solidification white spot listed in Table III. The depletion never reached the level of the "lean white spot" (Table III). The homogeneous material with white spot chemistry showed an increase in LCF life at the high strain range relative to the base chemistry and no significant effect at the low strain range. If we were to however test specimens with actual solidification white spots in the gage length we should probably not see significant loss in LCF at the high strain range as in the case of discrete white spots. This is because solidification white spots are less depleted in hardener elements.

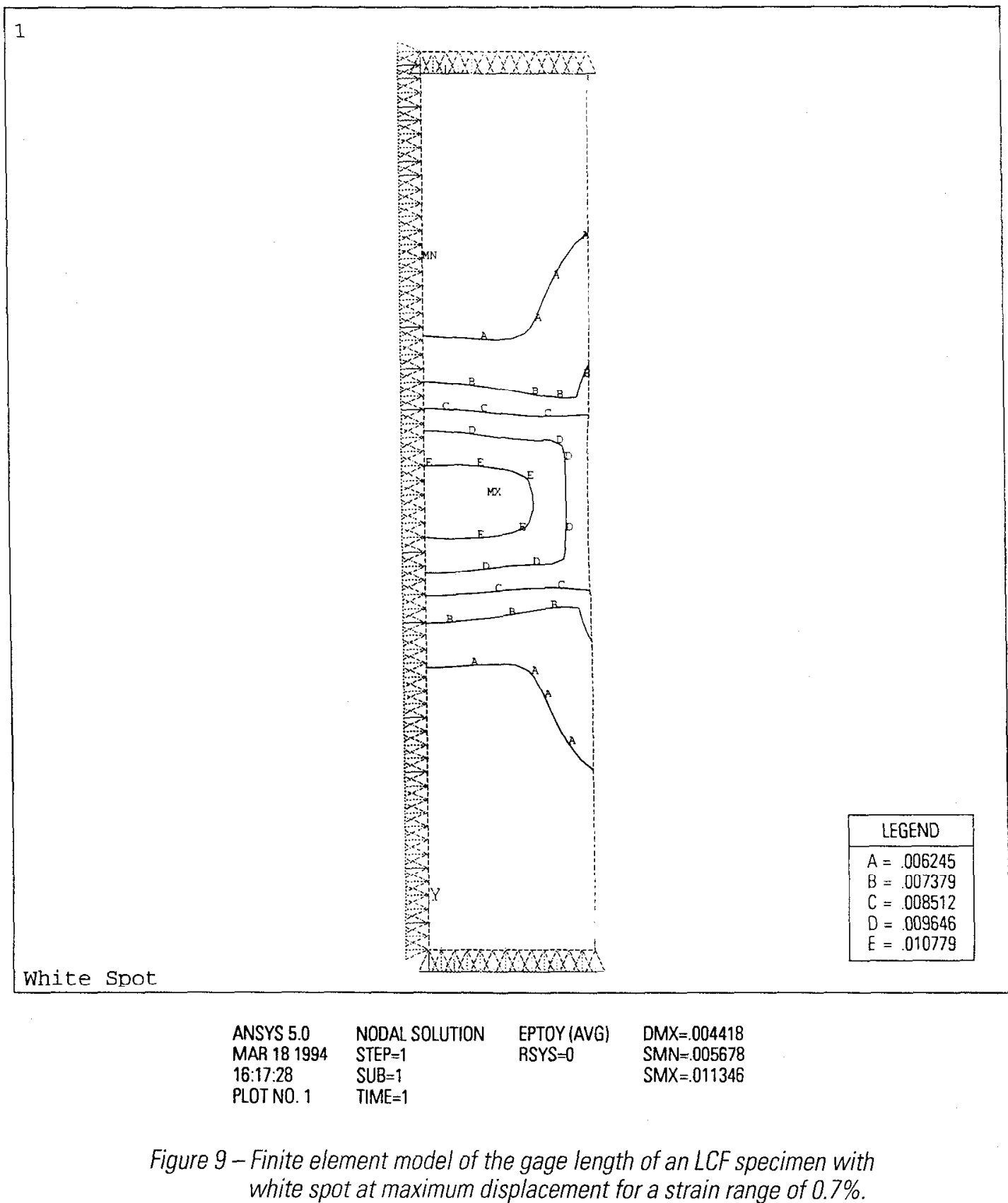




\section{$\underline{\text { Conclusions }}$}

1. Freckles degrade the mechanical properties significantly when the test axis is perpendicular to the plane of the freckles.

2. Freckle formation can be minimized through triple melting using VAR as the last step.

3. The VAR step must use a sound ingot and a low melt rate is preferred to avoid freckles.

4. Clean discrete white spots are not associated with larger grains than the matrix.

5. At strain ranges of $0.5 \%$ and below, clean discrete white spots do not reduce the LCF life significantly.

6. At high strain ranges of $0.7 \%$ and above there is a significant decrease in LCF life for clean discrete white spots.

7. Solidification white spots are expected to be associated with small decrease in strength, and increase in ductility and only slight changes in LCF life.

8. White spots do not have any significant effect on crack growth rate. 


\section{Acknowledgments}

The author would like to acknowledge the assistance of Hugh Ruble of the International Nickel Company for providing the small scale trial heats. Also acknowledged are the advice and technical discusions by Joe Pepe, Pete Schilke, Robin Schwant and D. K. Sharma during the course of this work.

\section{$\underline{\text { References }}$}

1. M.C. Flemings and G.E. Nereo, Transactions of the Metallurgical Society. AIME, 212 (1967) , 1449-1455

2. S. Kou, D.R. Poirer and M.C. Flemings, Metallurgical Transactions B, (1978) p 711

3. L.A. Jackman, G.E. Maurer and S. Widge. "New Knowledge About White Spots in Superalloys", Advanced Materials and Processes. May 1993. 18-25.

4. L. G. Hosami, W.E. Wood and J.H. Devletian, "Solidification of Alloy 718 During Vacuum Arc Remelting with Helium Gas Cooling Between Ingot and Crucible." Superalloy718 - Metallurgy and Applications (1989) TMS 49-57.

5. K.O. Yu and J.A. Domingue, Control of Solidification Structure in VAR and ESR Processed Alloy 718 Ingots", Superalloy 718 - Metallurgy and Applications (1989) TMS 33-48.

6. J.A. Domingue, K.O. Yu and H.D. Flanders, "Characterization of Macrosegregation in ESR IN-718", Fundamentals of Alloy Solidification Applied to Industrial Processes, NASA Lewis Research Center (1984) 1-11.

7. E.Samuelson, J.A. Domingue and G. Maurer. "Characterizing Solute-Lean Defects in Superalloys", Journal of Metals, 42 (8) (1990), 27-30.

8. S. Bourguinin, P. Martin and Y. Honnorat. "Segregation of Defects in Wrought Alloy 718 Management of Industrial Safeguards", Superalloy 718,625 and Various Derivatives.

TMS (1991), 193-204.

9. F.I. Shved, "An Analysis of the Mechanism of White Spot Formation", Journal of Metals, 46 (1) (1994), 36.

10. M.D. Evans and J.F. Radavich, "The Relationship of White Spots and Precipitation Reactions in Alloy 718", Proceedings of the 1989 Vacuum Metallurgy Conference. American Vacuum Society, (1989), 65-69. 